\title{
SABER E FAZER - UMA DIALÉTICA REFLEXIVA NA FORMAÇÃO DO CIDADÃO
}

\author{
Ticiana Fagundes da Porciuncula de Vilhena ${ }^{1}$, Gisele Lángaro Soares ${ }^{1}$, Ana Claudia Silveira \\ Ribeiro ${ }^{1}$, Julianne Marçal Munhoz ${ }^{1}$, Valdir Marcos Stefenon ${ }^{2}$ \\ ${ }^{1}$ Especialista em Educação pelo Programa de Pós Graduação lato sensu Educação: Interdisciplinaridade e \\ Transversalidade, Universidade Federal do Pampa, Campus São Gabriel \\ ticianaporciuncula@hotmail.com \\ 2 Professor Adjunto, Universidade Federal do Pampa, Campus São Gabriel \\ valdirstefenon@unipampa.edu.br
}

\section{RESUMO}

O presente artigo aborda a temática qualidade de vida escola como aspecto componente da formação do cidadão. A pesquisa foi realizada em uma escola de ensino fundamental de São Gabriel-RS, onde foram aplicados questionários que abrangiam questões referentes à estrutura física, escola ideal e aluno como protagonista da vida escolar. A partir dos dados coletados iniciouse uma pesquisa sobre a discrepância entre o que foi respondido e como é a realidade escolar. Conforme os resultados infere-se que os alunos tem a noção do que é certo e errado no ambiente escolar, mas atitudes não correspondem aos que os alunos descrevem como socialmente aceitos.

Palavras- chave: Ambiente escolar, Cidadania, Conscientização

\section{ABSTRACT}

This article addresses the issue of life quality in the school environment as an important component of the citizen building. The survey was conducted in an elementary school in São Gabriel-RS. Questionnaires were applied covering issues related to physical structure, the ideal school and the student as the protagonist of the school life. From the data collected it began a research on the discrepancy between what was answered and how the school reality is. According to the results it seems that the students have the notion of what is right and what is wrong at school, but some attitudes do not match to what students describe as socially acceptable.

Keywords: School Environment, Citizenship, Awareness

\section{INTRODUÇÃO}

O efetivo aprendizado escolar está relacionado a diversos fatores, entre os quais a qualidade de vida dos alunos, tanto dentro como fora da escola. A realidade observada previamente em escolas de Educação Básica do município de São Gabriel revela que o ambiente escolar de algumas instituições deixa a desejar no que se refere às condições consideradas adequadas para uma vivência e convivência saudáveis no que diz respeito desde as condições físicas do ambiente até o comportamento, hábitos e atitudes, principalmente, dos alunos. Este fato, por sua vez, aponta a necessidade de uma intervenção objetivando mudanças. 
O advento do século XXI trouxe mudanças na sociedade, nas relações humanas, no mercado de trabalho. A escola, entretanto, parece ser a que menos mudou, muitos passam por ela, mas pouco intervém de maneira positiva para o seu aprimoramento. Essas instituições educacionais não podem ficar alheias a essas mudanças, precisam desempenhar o seu papel social. A transformação, não só do sistema educacional, mas da sociedade, tem de passar pela escola. É preciso que um novo sentido de cidadania seja construído (FICAGNA e ORTH, 2010).

As mudanças podem começar pela escola, partindo do princípio de que todos passam (ou deveriam passar) por ela, pois as grandes transformações não se originam apenas de grandes feitos, mas de iniciativas do dia-a-dia, simples e persistentes. É essencial que a escola desperte nos alunos a capacidade de compreenderem e atuarem no mundo em que vivem, é preciso dar-lhes informações e formação para que possam atuar como cidadãos, organizando-se e defendendo seus interesses e da coletividade. Precisam, porém, aprender a respeitar regras, leis e normas estabelecidas (FICAGNA e ORTH, 2010).

Ao repensarem seu ambiente escolar e como podem atuar positivamente sobre ele, os alunos estarão também repensando o mundo em que vivem, ao serem inseridos nesse processo passarão a valorizar o seu meio, pois, se sentirão como sujeitos transformadores. Como bem diz Freire "meu papel no mundo não é só o de quem constata o que ocorre, mas também o de quem intervém como sujeito de ocorrências. Não sou apenas objeto da História, mas seu sujeito igualmente" (1996, p. 85). E completa afirmando que é preciso que constatemos a realidade, não somente para nos adaptarmos, mas para mudarmos. Essa constatação não nos levará à impotência, mas ao desejo de transformar (FREIRE, 1996).

Nesta perspectiva, faz-se necessário caracterizar os aspectos relacionados a hábitos, atitudes e comportamentos dos alunos em seu dia-a-dia escolar, de modo a identificar intervenções que possibilitem uma melhora na qualidade de vida dentro das escolas, formando cidadãos conscientes de seus direitos e deveres.

A presente pesquisa foi desenvolvida em uma escola da rede pública de São Gabriel, RS, com alunos do Ensino Fundamental, durante o ano letivo de 2011. Foram aplicados questionários, realizadas atividades lúdicas e observações do comportamento dos alunos, de modo a levantar as opiniões e atitudes dos alunos a respeito dos aspectos abordados.

O objetivo central do trabalho foi investigar os aspectos sociais e morais envolvidos na qualidade de vida na escola, considerando hábitos, atitudes e comportamentos referentes à formação de valores dos sujeitos envolvidos no espaço escolar.

\section{SABER É DIFERENTE DE FAZER}

Ficagna e Orth (2010) ressaltam que ao buscarmos informações fidedignas sobre a realidade escolar, estamos avaliando a situação e o processo envolvido, o que facilita o entendimento dos fatores que atrapalham o sucesso escolar. Segundo os mesmos autores, professores e alunos precisam "assumir a condição de seres históricos em permanente processo de construção e reconstrução, bem como problematizar o presente e o futuro". (2010, p. 254).

Segundo Minayo et al (2000), a Organização Mundial da Saúde (OMS) definiu como qualidade de vida "a percepção do indivíduo de sua posição na vida, no contexto da cultura e sistema de valores nos quais ele vive e em relação aos seus objetivos, expectativas, padrões e preocupações". Ou seja, a ideia de qualidade de vida depende de diversos fatores. Estes autores afirmam, ainda, que "qualidade de vida é uma noção eminentemente humana, que tem sido 
aproximada ao grau de satisfação encontrado na vida familiar, amorosa, social e ambiental e à própria estética existencial." A qualidade de vida deveria estar presente em todos os ambientes, mas na escola ela se faz ainda mais necessária, pois, é onde o sujeito é preparado para viver em sociedade e aprende a aprimorar o mundo onde vive. Mas, esse processo ensino-aprendizagem só ocorrerá em sua plenitude se o ambiente em que ele é realizado tiver as condições adequadas para que isto aconteça.

Segundo Liberal, Aires e Osório (2005) a escola é um dos pilares da educação, da construção da cidadania, da formação de um povo e de uma nação. É por meio dela que a criança inicia sua educação, sua integração e inclusão social, seus relacionamentos e seus potenciais, ou seja, relações complexas que se estendem por toda a vida.

Assim como a sociedade, o papel da escola vem mudando drasticamente nos últimos anos, ultrapassando a sua função acadêmica e passando a agregar a socialização, formação do caráter, comportamento e cidadania. Para isso, é importante que todos os seus atores estejam preparados para lidar com a multiplicidade de questões que envolvem a criança e o adolescente numa sociedade que os torna tão vulneráveis (LIBERAL, AIRES e OSÓRIO, 2005).

Ficagna e Orth (2010) afirmam que, a simples transmissão dos conteúdos e da cultura construída na escola, não prepara o aluno para as exigências da sociedade atual, enquanto o mundo anda muito rápido fora do contexto escolar, o aluno fica entre quatro paredes passivamente sentado, ouvindo os professores falarem ou realizando exercícios. Assim, é urgente que um novo sentido de cidadania seja construído e o lugar mais favorável para que isso aconteça é a escola. É onde as crianças e adolescentes passam uma boa parte de seu dia, é lá que passam a conviver com outras pessoas, fora de sua família e é lá que supostamente são preparadas para viver em sociedade. Freire também diz que "a educação é uma forma de intervenção no mundo. Intervenção que além do conhecimento dos conteúdos bem ou mal ensinados e/ou aprendidos implica tanto a reprodução da ideologia dominante quanto o seu desmascaramento" (FREIRE, 1996).

Para Pradel e Dáu (2009) o estado atual da sociedade brasileira, em que se percebe uma melhoria das condições objetivas de vida da população, paralelamente a uma degradação das atitudes éticas que norteiam essa mesma população, não pode deixar de levar o educador a se preocupar diretamente com a formação para valores. Essa situação leva à convicção de que, independente da matéria lecionada, o educador deve buscar a conscientização dos alunos sobre a importância da ação individual e coletiva para a transformação da sociedade em um espaço de convivência, reconhecimento e respeito às diferenças.

Tal preocupação não está baseada apenas em convicções individuais, mas na própria Constituição da República Federativa do Brasil, promulgada em 1988, na qual constam como objetivos fundamentais da República: construir uma sociedade livre, justa e solidária; garantir o desenvolvimento nacional; erradicar a pobreza e a marginalização e reduzir as desigualdades sociais e regionais; promover o bem de todos, sem preconceitos de origem, raça, sexo, cor, idade e quaisquer outras formas de discriminação (MEC, 2000).

E esta cidadania tem na educação uma parceira importante para seu desenvolvimento, em particular no tema transversal da ética, que

interroga sobre a legitimidade de práticas e valores consagrados pela tradição e pelo costume. Abrange tanto a crítica das relações entre os grupos, dos grupos nas instituições e perante elas, quanto à dimensão das ações pessoais. Trata-se portanto de discutir o sentido ético da convivência humana nas suas relações com várias dimensões da vida social (MEC, 2000, p. 30). 
Oriunda da Constituição, a referência brasileira de comportamento moral advém do convívio social e, desse modo, a preocupação é referir-se ao perfil democrático da sociedade brasileira, considerando o caráter abstrato dos valores. Complementar a essa visão, a ética vem equilibrar as relações a partir do pensar, do refletir e do construir nos diversos espaços. Do ponto de vista ético, os valores são os fundamentos da moral, das normas e regras que prescrevem a conduta correta. No entanto, a própria definição desses valores varia em diferentes doutrinas filosóficas. Para algumas concepções, é um valor tudo aquilo que traz a felicidade do homem. Alguns filósofos consideram também que os valores se caracterizam por relação aos fins que se pretendem obter, a partir dos quais algo se define como bom ou mau. Outros defendem a ideia de que algo é um valor em si mesmo (JAPIASSÚ; MARCONDES, 1996, p. 268 apud Pradel e Dáu, 2009).

Segundo Rodrigues (2001) o vocábulo cidadania, no caso, recebe sua definição do conjunto semântico que a expressão "exercício da cidadania" carrega. O texto constitucional sugere que o conceito de cidadania resulta de uma função social - a prática da cidadania - onde o seu significado emerge. Similar a todo conteúdo semântico, ele só é plenamente compreendido na relação com a vida social. Por seu lado, é o ato concreto do exercício da cidadania que dá sentido ao termo cidadão. Portanto, cidadania é um atributo aplicado ao cidadão e, mais importante ainda: recebe sua legitimidade na ação educativa.

De acordo com Perez et al (2008) é necessário que os indivíduos conquistem a cidade não por meio do conhecimento, mas também do amor e da identificação. Significa poderem descobrir que 'caminhos' podem ser trilhados, individual e coletivamente; significa poderem descobrir, com os outros, que a cidade não está pronta, mas é 'obra' a ser construída; significa poderem se sentir tendo a ver com os problemas e dificuldades da cidade, e não como algo que não lhes diz respeito. A cidadania constitui-se, portanto, de um sentimento construído internamente pelo sujeito por meio de sua ação.

$\mathrm{O}$ ato de formar o ser humano se dá em dois planos distintos e complementares: um de fora para dentro e outro, de dentro para fora. Pelo primeiro, ele "precisa ser educado" por uma ação que lhe é externa, de modo similar à ação dos escultores que tomam uma matéria informe qualquer e criam a partir dela outro ser. Assim como não se deve esperar que um objeto escultural aparecesse de modo espontâneo, também não se deve esperar que o ser humano fosse fruto de um processo de auto-criação. É ainda Kant quem reafirma que o homem não pode se tornar homem senão pela educação. A formação humana resulta de um ato intencional, que transforma a criatura biológica em um novo ser, um ser de cultura. Esse ato denomina-se Educação. Em resumo: a Educação é um ato intencional imposto de fora sobre uma criatura que deve ser formada como ser humano. Sendo um ato intencional e externo, ele é desempenhado primeiramente pelos que antecedem na vida social os que estão sendo formados (RODRIGUES, 2001).

Rosa e Galera (2011) citam Michel Foucalt quando este diz que a "docilização" produz um tipo de sociedade que favorece a uma teia de interesses e poder criando uma relação de submissão e disciplinação. Assim, o processo de transformação que poderia ocorrer a partir da escola fica enfraquecido e perdemos o sentido de pertencer.

De acordo com Pradel e Dáu (2009) o envolvimento afetivo e emocional dos educadores parece ser uma condição indispensável para que, a partir da exposição de experiências particulares e juntamente com uma prática do diálogo e de relações democráticas, seja efetuada a análise de conjuntura e a geração de práticas não coercitivas na escola. Com isso, torna-se possível que exerçam a condição de pensadores reflexivos e "formadores" culturalmente comprometidos para o desenvolvimento pleno do cidadão melhorando, assim, a própria prática. Para tanto, é necessário que os profissionais da educação sejam indivíduos solidamente formados, condição 
indispensável para a erradicação da ignorância ou do despreparo para a condução de um currículo educacional voltado para a formação em valores como caminho para uma sociedade efetivamente inclusiva. Tal modo de proceder ressalta a importância da prática docente como fruto de toda a sociedade, desenvolvida através dos diferentes meios e espaços sociais, com o propósito de estender o domínio da educação para os diversos contextos culturais e sociais, propiciando o pleno exercício da cidadania e não como uma reprodução mecânica ou pouco reflexiva de padrões pré-estabelecidos. Pelo fato de a educação moral, entretanto, ser mais aberta do que as disciplinas tradicionais e isso, em verdade, aplica-se a todo trabalho que lide com temas transversais ou que seja realizado de forma inter ou transdisciplinar parece que muitos profissionais não se sentem confiantes em relação à mesma.

\section{A REALIDADE OBSERVADA}

Como ferramenta para quantificar e qualificar questões sobre qualidade de vida no ambiente escolar foi aplicado um questionário para as turmas de $4 \underline{a}$ a $8^{a}$ séries do ensino fundamental contendo questões dirigidas relativas à conservação da escola. Levando em consideração as limitações da leitura e escrita, na pré-escola, 1a e 3a séries, o questionário foi aplicado de forma oral com a utilização de plaquinhas (tá legal e não tá legal). Com as turmas da 2a serie não foi possível aplicar o questionário pela incompatibilidade de horários. Além do questionário, foi feita uma atividade lúdica com alunos da oitava serie, na qual havia um jogo que abordava a qualidade de vida da escola. A partir deste jogo foi proposta confecção de cartazes sobre o que eles haviam aprendido com o jogo e o que eles gostariam de mostrar para os outros alunos, interagindo com os menores e deixando sua marca positiva na escola, já que os cartazes foram fixados por toda escola. Ao total foram entrevistados 116 alunos.

A partir da metodologia utilizada, observou-se que algumas respostas não condiziam com a realidade observada no ambiente escolar. Respostas referentes à limpeza e conservação da mobília da escola nos mostraram que os alunos "sabem" o que deve ser feito para manter a escola limpa (Figuras 1 e 2), entretanto havia papeis e lixo jogados em lugares inapropriados para tal.

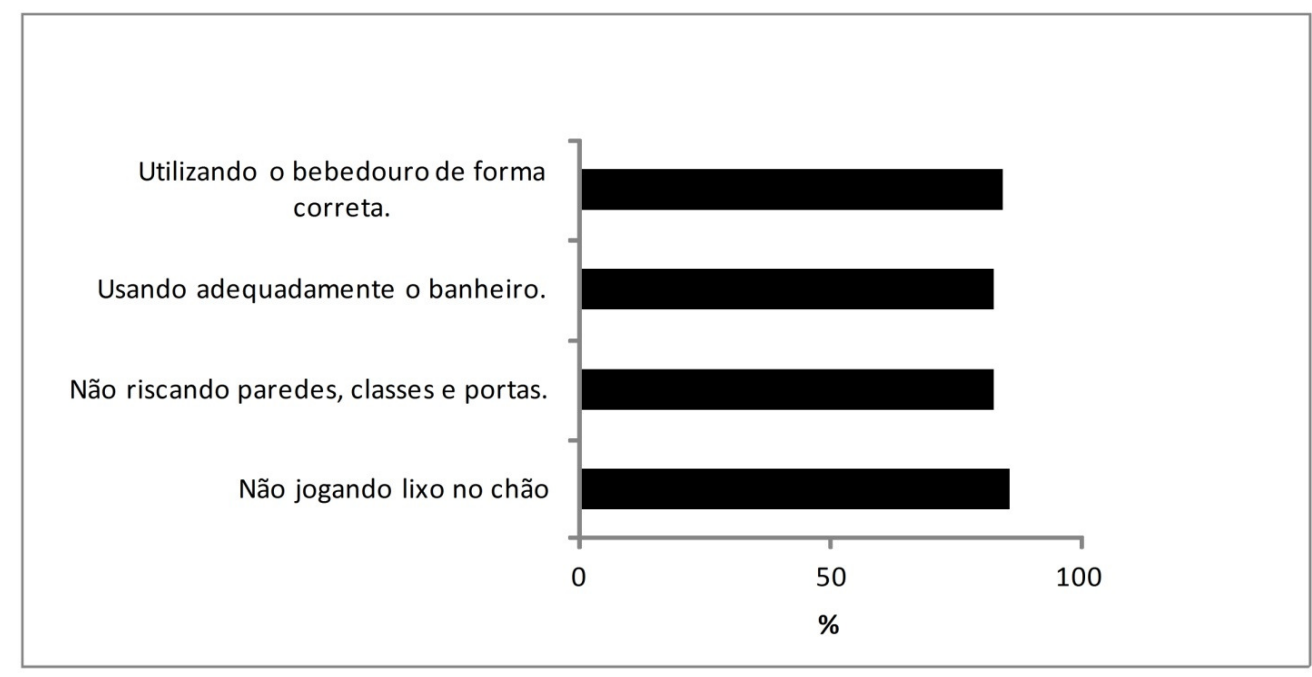


Figura 1. Porcentagem dos alunos de quarta a oitava séries $(n=71)$ que afirma tomar as atitudes listadas frente à questão: você colabora com a manutenção da limpeza de sua escola?

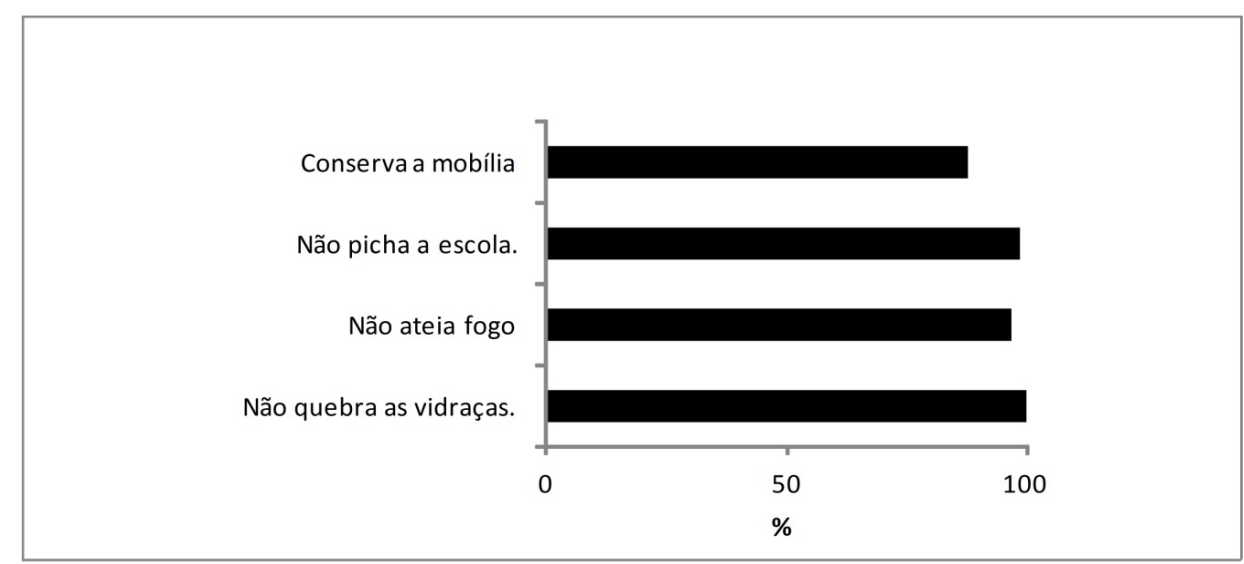

Figura 2. Porcentagem dos alunos de quarta a oitava séries $(n=71)$ que afirma tomar as atitudes listadas frente à questão: que atitudes você toma para cuidar de sua escola?

Aos alunos de pré-escola à terceira serie foi realizado outro tipo de abordagem, como mencionamos anteriormente, mas que não difere das respostas dos alunos das turmas mais avançadas. Na figura 3 podemos notar, entretanto, que nos conceitos conservação de mobília e vidraças, os estudantes demonstram uma pequena porcentagem maior de insatisfação. Esta quase satisfação sugere que estas crianças nunca se depararam com outra realidade, a maioria estuda nesta escola desde a pré-escola.

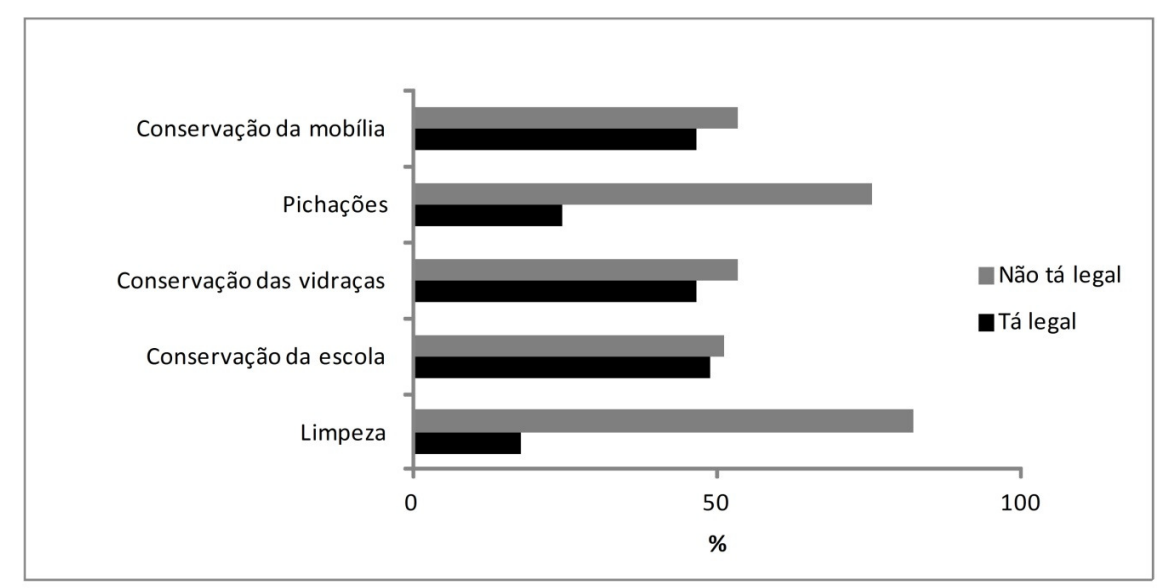

Figura 3. Porcentagem de alunos de pré a terceira serie que consideram que cada aspecto listado está ou não adequado dentro do ambiente escolar $(n=45)$.

A partir destas constatações, infere-se que os alunos sabem o que é socialmente aceito pela escola, quais são suas regras e como devem se comportar frente a determinadas situações, mas que apesar disso, suas atitudes e comportamentos não condizem com suas falas. A 
conscientização do que dever ser feito para manter a escola conservada parece não estar não arraigada nestes alunos.

A capacidade de agir e refletir é a primeira condição para que uma pessoa possa assumir um ato comprometido. Quando uma pessoa é capaz de ao estar no mundo, saber-se nele, também possui, então, a capacidade de direcionar a sua consciência para a forma de estar sendo, que condiciona sua consciência de estar.

A conscientização refere-se ao desenvolvimento crítico da tomada de consciência, implicando a ultrapassagem da esfera espontânea de apreensão da realidade e chegando a uma esfera crítica em que a realidade dá-se como objeto cognoscível e em que o sujeito assume uma posição epistemológica. É fundamental que todo aprendizado esteja relacionado intimamente à tomada de consciência de uma situação real e vivida pelo sujeito que aprende. A visão dialética recusa a compreensão da consciência como puro reflexo da objetividade material, como também demonstra a incompatibilidade entre ela e a ideia de um amanhã inexorável (FREIRE, 2000).

\section{CONSIDERAÇÕES FINAIS}

Freire (1996) nos diz que ensinar não é transferir conhecimentos, conteúdos, nem formar, é ação pela qual um sujeito criador dá forma, estilo ou alma a um corpo indeciso e acomodado. Não há docência sem discência, as duas se explicam e seus sujeitos, apesar das diferenças que os conotam, não se reduzem à condição de objeto, um do outro. Quem ensina aprende ao ensinar e quem aprende ensina ao aprender. O professor que pensar certo deixa transparecer aos educandos que uma das 'bonitezas' de nossa maneira de estar no mundo e com o mundo, como seres históricos, é a capacidade de intervindo no mundo, conhecer o mundo.

Entretanto muitos professores não correspondem a essas expectativas, não se mostram conscientizadores, nem educadores, somente ministram aulas, sem imprimir sua marca, sem fazer da sala da aula um lugar facilitador de conhecimento e consciência.

Precisamos então, entender porque os alunos picham paredes, quebram a mobília da escola, sem deixar sua marca positiva, uma vez que os mesmos compreendem que tais atitudes são erradas socialmente, como constatado que referem-se a atitudes positivas em relação à manutenção da escola: "Você colabora com a manutenção da limpeza de sua escola, de que forma?" e "Que atitudes você toma para cuidar da sua escola?" A grande maioria respondeu que não quebra vidraças, não ateia fogo, não picha a escola (riscar as paredes), conserva a mobília (Figuras 1 e 2), entretanto a realidade encontrada na escola foi diferente, lixo no chão da sala, paredes riscadas, mobílias em péssimo estado de conservação.

Ora, se a tomada de consciência resulta da defrontação do sujeito com o mundo, com a realidade concreta, espera-se que pais e educadores orientem seus filhos e alunos, confronte-os com a realidade observada para que eles não sejam meros sujeitos, mas sim cidadãos que exercem suas cidadanias desde pequenos em suas salas de aula ou em casa, sendo agentes de uma sociedade capaz de conscientizar as gerações futuras.

\section{REFERÊNCIAS BIBLIOGRÁFICAS}

FICAGNA, Marisa; ORTH, Miguel Alfredo. Educação para um novo cidadão: construindo possibilidades ou relações entre a teoria e a prática. In: ANDREOLA, Balduino Antonio et al. (orgs). 
Formação de educadores: da itinerância das universidades à escola itinerante. ljuí: Ed. Unijuí, 2010. p.247-259.

FREIRE, Paulo. Pedagogia da autonomia: saberes necessários à prática educativa. 6. ed. São Paulo: Paz e Terra, 1996.

. Pedagogia da esperança: um reencontro com a Pedagogia do Oprimido. São Paulo: Paz e Terra, 2000.

LIBERAL, Edson et al. Escola segura. In: Jornal de Pediatria v.81 n.5. Rio de Janeiro, 2005.

MINAYO, Maria Cecília de Souza; HARTZ, Zulmira Maria de Araújo; BUSS, Paulo Marchiori. Qualidade de vida e saúde: um debate necessário. Ciência e Saúde Coletiva, v. 5, n. 1, p. 7-18, 2000.

MEC, Secretaria de Educação Fundamental. Parâmetros Curriculares Nacionais: apresentação dos temas transversais: ética. Brasília, DF: 2000.

PÉREZ, Beatriz et al. Cidadania e participação social: um estudo com crianças no Rio de Janeiro. In: Psicologia \& Sociedade v.20 n.2. Porto Alegre, 2008.

PRADEL, Claudia e DÁU, Jorge Alberto. A educação para valores e as políticas públicas educacionais. In: Ensaio: Avaliação e Políticas Publicas em Educação. v.17 n.64. Rio de Janeiro jul/set. 2009.

RODRIGUES, Nelson. Educação: da formação humana à construção do sujeito ético. In: Educação \& Sociedade. v.22 n.76. Campinas out. 2001

ROSA, Eloisa; GALERA; Joscejy Bassetto. A gestão do espaço físico escolar: um desafio social. Disponível em: <http://www.diaadiaeducacao.pr.gov.br/portals/pde/arquivos/1699-8.pdf>. Acesso em: 2 jul. 2011. 